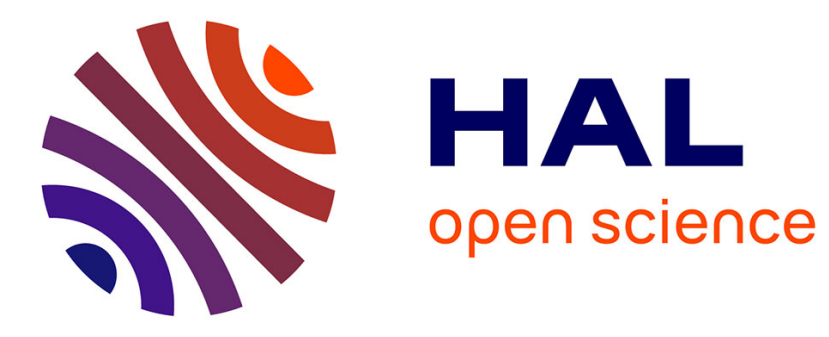

\title{
Ge/SiGe Quantum well optical modulator
}

Delphine Marris-Morini, Vladyslav Vakarin, Papichaya Chaisakul, Jacopo

Frigerio, Mohamed-Saïd Rouifed, Xavier Le Roux, Daniel Chrastina, Laurent

Vivien, Giovanni Isella

\section{- To cite this version:}

Delphine Marris-Morini, Vladyslav Vakarin, Papichaya Chaisakul, Jacopo Frigerio, Mohamed-Saïd Rouifed, et al.. Ge/SiGe Quantum well optical modulator. 25th international conference on Solid State Device and Materials (SSDM2015),, Sep 2015, Sapporo, Japan. hal-01322037

\section{HAL Id: hal-01322037 https://hal.science/hal-01322037}

Submitted on 26 May 2016

HAL is a multi-disciplinary open access archive for the deposit and dissemination of scientific research documents, whether they are published or not. The documents may come from teaching and research institutions in France or abroad, or from public or private research centers.
L'archive ouverte pluridisciplinaire HAL, est destinée au dépôt et à la diffusion de documents scientifiques de niveau recherche, publiés ou non, émanant des établissements d'enseignement et de recherche français ou étrangers, des laboratoires publics ou privés. 


\title{
Ge/SiGe Quantum well optical modulator
}

\author{
Delphine Marris-Morini ${ }^{1}$, Vladyslav Vakarin ${ }^{1}$, Papichaya Chaisakul ${ }^{1,2}$, Jacopo Frigerio ${ }^{3}$, \\ Mohamed-Saïd Rouifed ${ }^{1}$, Xavier Le Roux ${ }^{1}$, Daniel Chrastina ${ }^{3}$, Laurent Vivien ${ }^{1}$, Giovanni Isella ${ }^{3}$ \\ ${ }^{1}$ Institut d'Electronique Fondamentale, Univ. Paris-Sud, CNRS UMR 8622, \\ Bât. 220, 91405 Orsay, France \\ ${ }^{2}$ Departement of Material Engineering, The University of Tokyo, Japan \\ Polo di Como, Via Anzani 42, I 22100 Como, Italy \\ ${ }^{3}$ L-NESS, Dipartimento di Fisica, Politecnico di Milano, \\ Polo di Como, Via Anzani 42, I 22100 Como, Italy
}

\begin{abstract}
Ge/SiGe Quantum well structures have a strong potential to revolutionize silicon photonics. This paper reviews recent works including high speed modulation, QW engineering to tune the wavelength and waveguide integration.
\end{abstract}

\section{Introduction}

The interest in silicon photonics is continuously growing as it is now considered to have potential applications in telecommunication and data communications. In this context, Ge has been proposed by a few research groups as the material of choice for the realization of a complete photonic circuit. Despite being an indirect band gap material, its absorption is "direct gap like" thanks to the small energy difference between the direct and indirect bandgaps. Moreover, it is a group IV material, compatible with fabrication in CMOS foundries. Among Ge-based structures, Ge rich-Ge/SiGe quantum wells $(\mathrm{QW})$ have received a growing interest, as the quantum confinement in Ge wells allow additional features with respect to the bulk materials, such as more abrupt band-edge absorption, the presence of excitonic features as well as the possibility of band structure engineering.

The first demonstration of a direct gap-related optical property in $\mathrm{Ge} / \mathrm{SiGe} \mathrm{QW}$ was the observation of the quantum-confined Stark effect (QCSE) [1,2]. These results paved the way to a number of exciting works addressing not only the electro-absorption but also the electro-refraction [3] mechanisms in $\mathrm{Ge} / \mathrm{SiGe} \mathrm{QW}$ structures and tackling the realization of innovative optoelectronic devices.

Recent advances in the theoretical and experimental studies of $\mathrm{Ge} / \mathrm{SiGe}$ quantum wells structures will be presented with a focus on optical telecommunication applications. Firstly, high-speed stand-alone Ge/SiGe QW electro-absorption modulators will be reported, followed by the presentation of different methods for engineering $\mathrm{Ge} / \mathrm{SiGe}$ QW to tune the operating wavelength to $1.3 \mu \mathrm{m}$. Finally different solutions to integrate $\mathrm{Ge} / \mathrm{SiGe} \mathrm{QW}$ devices with low-loss waveguides will be presented.

\section{High speed modulator}

QCSE leads to a strong variation of absorption coefficient around the absorption band-edge of $\mathrm{Ge} / \mathrm{SiGe} \mathrm{QW}$ structures This effect has first been used to demonstrate high speed modulation. The stand-alone modulator is reported in Fig 1. It is based on a $3 \mu \mathrm{m}$-width, $90 \mu \mathrm{m}$-long waveguide embedded $\mathrm{Ge} / \mathrm{Si}_{0.15} \mathrm{Ge}_{0.85} \mathrm{QW}$ inserted in a PIN diode. The QW are grown on a $\mathrm{Si}_{0.1} \mathrm{Ge}_{0.9}$ relaxed buffer using a strain compensated design, and a $13 \mu \mathrm{m}$-thick graded buffer between $\mathrm{Si}$ and $\mathrm{Si}_{0.1} \mathrm{Ge}_{0.9}$ is used to manage the lattice mismatch between $\mathrm{Si}$ and $\mathrm{Si}_{0.1} \mathrm{Ge}_{0.9}$ and to minimize the threading dislocations density [4].

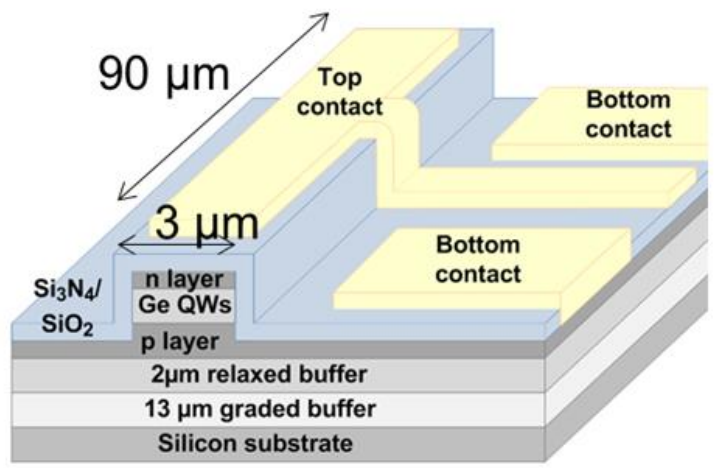

Fig. 1. Schematic view of a Ge/SiGe QW modulator in a waveguide configuration

A high extinction ratio up to more than $10 \mathrm{~dB}$ is obtained while an extinction ratio larger than $6 \mathrm{~dB}$ is reported in a $20 \mathrm{~nm}$ wavelength range. The electro-optic bandwidth is measured larger than $20 \mathrm{GHz}$, while the power consumption is less than $100 \mathrm{fJ} / \mathrm{bit}$.

\section{Ge/SiGe Quantum well engineering}

As a main advantage, QW can be engineered to obtain significant QCSE around the telecommunication wavelength of $1.3 \mu \mathrm{m}$. In the first demonstrations, $\mathrm{Ge} / \mathrm{Si}_{0.15} \mathrm{Ge}_{0.85} \mathrm{QW}$ grown on $\mathrm{Si}_{0.1} \mathrm{Ge}_{0.9}$ virtual substrate lead to QCSE at 1.42 $\mu \mathrm{m}$. Different methods can be used to decrease the operating wavelength. Firstly, knowing that a higher level of compressive strain on Ge allows increasing its bandgap energy, a design has been proposed based on $\mathrm{Ge} / \mathrm{Si}_{0.35} \mathrm{Ge}_{0.65}$ QW grown on $\mathrm{Si}_{0.21} \mathrm{Ge}_{0.79}$. As predicted, a strong absorption 
variation has been obtained at $1.3 \mu \mathrm{m}$ [6]. A second way to decrease the operating wavelength of the widely-used $\mathrm{Ge} / \mathrm{Si}_{0.15} \mathrm{Ge}_{0.85} \mathrm{QW}$ grown on $\mathrm{Si}_{0.1} \mathrm{Ge}_{0.9}$ is to increase QW confinement energy by varying the quantum well thickness. As an example, the absorption spectra of a structure made of $6.5 \mathrm{~nm}$-thick Ge well is reported in Fig. 2, showing a strong QCSE within the O-band telecommunication wavelength, verifying the potential to use this structure for high extinction ratio and moderate absorption loss modulator over 30-nm-wide spectral range from 1330 to $1360 \mathrm{~nm}$.

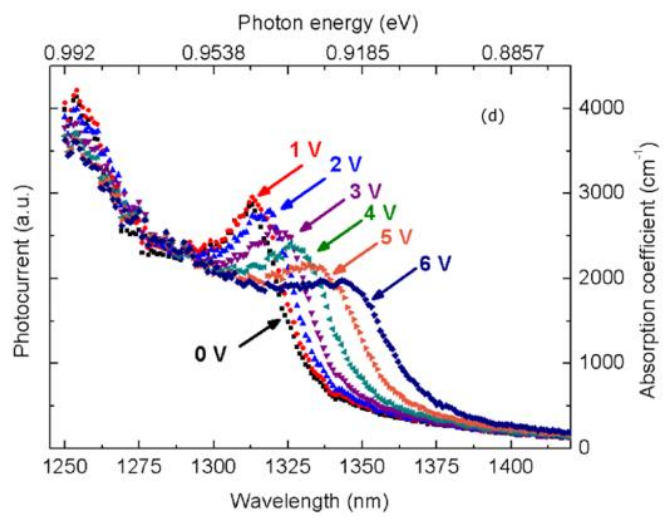

Fig.2. QCSE in Ge/SiGe QW using $6.5 \mathrm{~nm}$-thick $\mathrm{Ge} / \mathrm{Si}_{0.15} \mathrm{Ge}_{0.85} \mathrm{QW}$ grown on $\mathrm{Si}_{0.1} \mathrm{Ge}_{0.9}$

\section{Waveguide integration}

The main challenging point of Ge/SiGe QW-based devices is their integration with silicon on insulator (SOI) waveguides because of the need of a virtual substrate between $\mathrm{Si}$ and Ge-rich structures. We are currently considering two possible integration schemes.

In a first approach we proposed a new strategy of integrating $\mathrm{Ge} / \mathrm{SiGe} \mathrm{QW}$ devices with silicon wafers, based on the use of SiGe waveguides using the linear index increasing in the graded buffer. Light can then be coupled in the QW using tapered waveguides for the active devices as illustrated in Fig 3. As a main challenge the Ge concentration in the SiGe waveguide should allow simultaneously a low loss waveguide and a good crystalline quality of the $\mathrm{Ge} / \mathrm{SiGe} \mathrm{QW}$ active region. Using this approach, an optical link based on a passive $\mathrm{Si}_{0.16} \mathrm{Ge}_{0.84}$ waveguide and optoelectronic $\mathrm{Ge} / \mathrm{Si}_{0.16} \mathrm{Ge}_{0.84}$ QWs devices including an optical modulator and a photodetector has been demonstrated. [8]

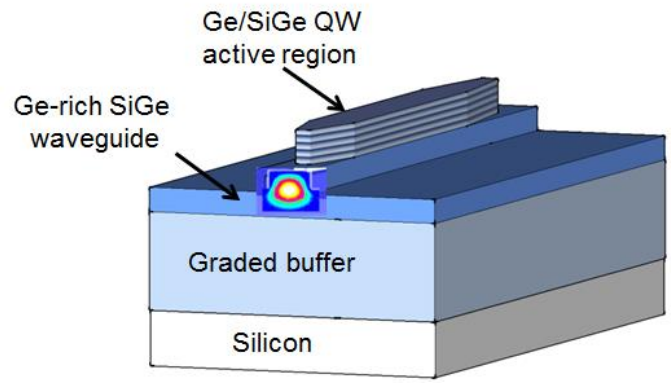

Fig.3. Integration of $\mathrm{Ge} / \mathrm{SiGe} \mathrm{QW}$ devices with Ge-rich SiGe waveguide on graded SiGe buffer.
When considering high data rate communications based on polarization and wavelength multiplexing, the integration of Ge/SiGe QW structures with SOI waveguide would allow benefiting from both compact and low power consumption active devices and efficient and compact passive building blocks such as AWG. Such integration requires a reduction of the thickness of the buffer layer between $\mathrm{Ge} / \mathrm{SiGe} \mathrm{QW}$ and silicon wafer. To this purpose, we developed a relaxed buffer with $360 \mathrm{~nm}$ thickness that would practically allow the optical coupling between a SOI waveguide and the $\mathrm{Ge} / \mathrm{SiGe} \mathrm{QW}$ active region [9]. We then theoretically investigated properties of a QW modulator integrated on SOI waveguides. $8 \mathrm{~dB}$ ER were predicted with only $4 \mathrm{~dB}$ optical insertion loss.

\section{Conclusions}

The recent reports of high speed modulator and photodetector, electro-refraction, wavelength tuning by engineering $\mathrm{Ge} / \mathrm{SiGe} \mathrm{QW}$ and waveguide integration has demonstrated the strong potential of these structures for silicon photonics.

\section{Acknowledgements}

This work is supported by the CARIPLO foundation through the grant EIDOS 2011-038, by Marie Curie International Outgoing Fellowships through grant agreement PIOF-GA-2013-629292 and by the European Research Council under the ERC Starting Grant INsPIRE $n^{\circ} 639107$.

\section{References}

[1] Y. Kuo et al., Nature, 437, 1334 (2005)

[2] P. Chaisakul et al, Optics Letters, 35 (17) 2913 (2010).

[3] J. Frigerio et al., Applied Physics Letters 102, 061102 (2013).

[4] P. Chaisakul et al., Optics Express, 20 (3), 3219-3225, (2012)

[5] P. Chaisakul et al., IEEE Photonics Technology Letters, 23 (20), (2011).

[6] M-S. Rouifed. et al., Optics Letters 37, 3960 (2012).

[7] P. Chaisakul et al., Journal of Applied Physics, 116, 193103 (2014).

[8] P. Chaisakul et al., Nature Photonics 8, 482-488 (2014).

[9] M-S. Rouifed., et al IEEE J Sel Top Quant Electron, 20, 33-39 (2014 